\title{
GAMBARAN TINGKAT STRES PADA LANSIA DI PANTI JOMPO KOTA LHOKSEUMAWE TAHUN 2017
}

\author{
Khaidir $^{1 *}$, Nora Maulina ${ }^{2}$ \\ ${ }^{1}$ Program Studi Kedokteran fakultas Kedokteran universitas Malikussaleh \\ ${ }^{2}$ Bagian Fisiologi Fakultas Kedokteran Universitas Malikussaleh \\ *Corresponding author : nora.maulina@unimal.ac.id
}

\begin{abstract}
Abstrak
Menua atau menjadi tua adalah suatu keadaan yang terjadi di dalam kehidupan manusia. Apabila seseorang memasuki masa usia lanjut, terjadi berbagai perubahan baik yang bersifat fisik, mental, maupun sosial. Perubahan-perubahan tersebut akan menempatkan individu usia ini pada posisi serba salah yang akhirnya hanya menjadi sumber akumulasi stres dan frustasi belaka. Stres dapat menyerang semua orang, baik anak-anak, orang dewasa maupun lanjut usia (lansia). Penelitian ini bertujuan untuk mengetahui gambaran tingkat stres pada lansia di panti jompo kota lhokseumawe tahun 2017. Jenis penelitian ini adalah deskriptif dengan pendekatan croos sectional dengan tekhnik pengambilan sampel menggunakan metode total sampling. Jumlah sampel yang diambil sebnyak 55 responden. Hasil dari penelitian ini memperlihatkan bahwa tingkat stres paling tinggi adalah tingkat stres sedang yaitu sebanyak 25 orang $(45,4 \%)$, tingkat depresi paling tinggi yaitu depresi sedang sebanyak 25 orang $(45,4 \%)$, tingkat kecemasan tertinggi yaitu normal sebanyak 19 orang $(34,5)$, didapatkan juga usia terbanyak yaitu usia 60-74 sebanyak 31 orang $(56,3 \%)$, didapatkan juga lansia dengan jenis kelamin terbanyak adalah perempuan sebanyak 34 orang $(61,9 \%)$, didapatkan juga lansia terbanyak berpendidikan dasar (SD/SMP) yaitu sebanyak 40 orang $(72,8 \%)$.
\end{abstract}

Kata Kunci : Tingkat stres lansia; Usia; Jenis kelamin; Pendidikan

\section{Description Stress Level of Elderly at Nursing Home Lhokseumawe in 2017}

\begin{abstract}
Aging or getting old is a condition that occur in human life. When human enters the elderly, they will getting various change both physically, mental and social. The changes will make the elderly in wrong position and finally its only make the accumulation of stress and frustation. Stress can attack every one, both children, adult and the elderly. This research aims to know the description of stress levels in the elderly at Nursing Home Lhokseumawe on 2017. This type of research is descriptive with cross sectional approach and sampling technique using total sampling method. The samples taken to 55 respondents. The results of this study describe that the highest stress level is moderate stress as many as 25 respondents $(45,4 \%)$, the highest depression level is moderate depression as many as 25 respondents $(45,4 \%)$, the highest worry level is normal as many as 19 respondents $(34,5 \%)$, with the age of most respondents is the age of 60-74 years as many as 31 respondents $(56,3 \%)$, with the most sex of respondents being women as many as 34 respondents $(61,9 \%)$, with most respondents education is primary school ( $\mathrm{SD} / \mathrm{SMP})$ as many as 40 respondents $(72,8 \%)$.

Keywords : Stress levels of the elderly; Age; Sex; Education
\end{abstract}

Jurnal Averrous Vol.4 No.1 2018 


\section{PENDAHULUAN}

Penduduk lanjut usia di dunia pada tahun 2012 mencapai 680 juta jiwa dan yang mengalami stres sekitar $32 \%{ }^{1}$. Penduduk lanjut usia di atas 65 tahun pada tahun 2000 di Swedia ada $17,4 \%$, Belgia 16,4\%, Inggris 16\%, Jerman 15,9\% dan Denmark 15,2\% ${ }^{2}$. Penduduk di sebelas negara kawasan Asia Tenggara yang berusia di atas 60 tahun berjumlah 124 juta orang dan diperkirakan akan terus meningkat sehingga tiga kali lipat di tahun 2050 ${ }^{1}$. Data Badan Pusat Statistik Provinsi Aceh menunjukkan bahwa jumlah lansia di Provinsi Aceh terus meningkat dari 5,3 juta jiwa (2009), menjadi 14,4 juta jiwa (2010) dan diperkirakan pada tahun 2020 mencapai 28,8 juta jiwa. Jumlah lansia di Kota Lhokseumawe terus meningkat dari 5,3 ribu jiwa (2008) menjadi 14,4 ribu jiwa (2010) ${ }^{3}$. Apabila seseorang memasuki masa usia lanjut, terjadi berbagai perubahan baik yang bersifat fisik, mental, maupun sosial. Proses alamiah adalah proses perkembangan manusia sejak periode awal sampai masa usia lanjut merupakan kenyataan yang tidak bisa dihindari dan mengalami berbagai perubahan-perubahan yang menyertai proses perkembangan ketika orang tersebut memasuki masa usia lanjut. Perubahan-perubahan tersebut akan menempatkan individu usia ini pada posisi serba salah yang akhirnya hanya menjadi sumber akumulasi stres dan frustasi belaka ${ }^{4}$.Data awal yang telah peneliti kumpulkan menunjukkan bahwa jumlah lansia di Kota Lhokseumawe berkisar 1,8ribu jiwa (2017) dan mempunyai dua panti jompo yaitu Panti Jompo Darussa'adah dengan jumlah lansia sebanyak 60 orang dan Panti Jompo An-Nur berjumlah 24 orang $^{\mathbf{5}}$. Lansia yang dominan lebih memilih tinggal di panti jompo daripada di kota, dikarenakan secara psikis mereka membutuhkan lingkungan yang mengerti dan memahami mereka. Lansia membutuhkan teman yang sabar, yang mengerti dan memahami kondisinya. Mereka membutuhkan teman ngobrol, dikunjungi kerabat atau keluarganya, dan sapaan yang sejuk serta sangat senang jika didengarkan nasehatnya. Dengan demikian dapat menurunkan gejala stres yang dialaminya ${ }^{6}$

Jurnal Averrous Vol.4 No.1 2018 


\section{METODE PENELITIAN}

\section{Desain penelitian}

Penelitian ini adalah jenis penelitian deskriptif dengan pendekatan cross-sectional. Lokasi yang dipilih untuk penelitian ini adalah Panti Jompo Darussa'dah dan An-Nur di Kota Lhokseumawe.

\section{Populasi dan sampel penelitian}

Populasi dalam penelitian ini adalah seluruh lansia di Kota Lhokseumawe tahun 2017 yaitu sebanyak 80 orang. Sampel dalam penelitian ini adalah lansia di panti jompo Kota Lhokseumawe yang memenuhi criteria inklusi dan eksklusi. Adapun kriteria inklusi dan eksklusi dalam penelitian ini adalah:

Kriteria inklusi:

1. Lansia yang tercatat sebagai penghuni Panti Jompo Darussa'adah dan An-Nur di Kota Lhokseumawe.

2. Bersedia menjadi subjek penelitian.

Kriteria eksklusi:

1. Lansia yang mengalami gangguan verbal / pendengaran / penglihatan.

2. Lansia yang mengkonsumsi obat antidepresan.

3. Lansia yang berusia $>90$ tahun.

\section{Pengambilan sampel}

Teknik pengambilan sampel menggunakan teknik total sampling yaitu sampel yang memenuhi kriteria inklusi dan eksklusi yaitu sebanyak 55 sampel. Lansia tiap Panti Jompo Kota Lhokseumawe berdasarkan kriteria inklusi yaitu Panti Jompo Darussa'adah sebanyak 41 sampel dan Panti Jompo An-Nur sebanyak 14 sampel.

\section{Hasil Penelitian dan Analisis}

Karakteristik Lansia Panti Jompo Darussa'dah dan An-Nur di Kota Lhokseumawe

Sampel dalam penelitian ini adalah lansia yang berada di Panti Jompo Darussa'dah dan An-Nur di Kota Lhoekseumawe sebanyak 55 orang. Berdasarkan hasil penelitian didapatkan data sebagai berikut: 
Tabel 5.1 Gambaran karakteristik berdasarkan usia

\begin{tabular}{ccc}
\hline & $\begin{array}{c}\text { Frekuensi } \\
(\mathrm{n})\end{array}$ & Persentase (\%) \\
\hline $45-59$ & 16 & 29,2 \\
tahun & 31 & 56,3 \\
$60-74$ & 8 & 14,5 \\
tahun & & \\
$75-90$ & & \\
tahun & & \\
\hline Total & 55 & 100 \\
\hline
\end{tabular}

Tabel 5.1 menunjukkan bahwa sebagian responden berumur 60-74 tahun sebanyak 31 orang (56,3\%), diikuti umur 45-59 tahun sebanyak 16 orang (29,2\%), dan paling sedikit umur 75-90 tahun sebanyak 8 orang $(14,5 \%)$.

Tabel 5.2 Gambaran karakteristik berdasarkan jenis kelamin

\begin{tabular}{lcc}
\hline & $\begin{array}{c}\text { Frekuensi } \\
(\mathrm{n})\end{array}$ & $\begin{array}{c}\text { Persentase } \\
(\%)\end{array}$ \\
\hline Laki-laki & 21 & 38,1 \\
Perempuan & 34 & 61,9 \\
\hline Total & 55 & 100 \\
\hline
\end{tabular}

Tabel 5.2 menunjukkan bahwa responden jenis kelamin yang terbanyak adalah Perempuan $(61,9 \%)$ dan paling sedikit pada Laki-laki $(38,1 \%)$.

Tabel 5.3 Gambaran karakteristik berdasarkan pendidikan

\begin{tabular}{ccc}
\hline & $\begin{array}{c}\text { Frekuensi } \\
(\mathrm{n})\end{array}$ & $\begin{array}{c}\text { Persentase } \\
(\%)\end{array}$ \\
\hline Dasar & 40 & 72,8 \\
$\begin{array}{c}\text { (SD/SMP) } \\
\text { Menengah }\end{array}$ & 13 & 23,6 \\
$\begin{array}{c}\text { (SMA) } \\
\text { Tinggi } \\
\text { (Perguruan } \\
\text { tinggi) }\end{array}$ & 2 & 3,6 \\
\hline Total & 56 & 100 \\
\hline
\end{tabular}


Tabel 5.3 menunjukkan bahwa pendidikan yang terbanyak adalah dari golongan dasar (SD/SMP) yaitu sebanyak 40 orang (72,8\%), diikuti golongan menengah (SMA) sebanyak 13 orang $(23,5 \%)$ dan yang paling sedikit dari golongan perguruan tinggi yaitu sebanyak 2 orang $(3,6 \%)$.

Tabel 5.4 Gambaran frekuensi berdasarkan tingkat stres pada lansia di Panti Darussa'dah dan An-Nur di Kota Lhokseumawe

\begin{tabular}{lcc}
\hline & $\begin{array}{c}\text { Frekuensi } \\
(\mathrm{n})\end{array}$ & Persentase (\%) \\
\hline Tidak mengalami stres & 8 & 14,5 \\
Stres ringan & 14 & 25,4 \\
Stres sedang & 25 & 45,4 \\
Stres berat & 8 & 14,5 \\
\hline Total & 56 & 100,0 \\
\hline
\end{tabular}

Berdasarkan tabel 5.4 menunjukkan bahwa sebagian besar responden memiliki tingkat stres sedang sebanyak 25 orang $(45,4 \%)$, diikuti tingkat stres ringan sebanyak 14 orang $(25,4 \%)$, dan paling sedikit tidak memiliki stres sebanyak 8 orang $(14,5 \%)$ dan stres berat sebanyak 8 orang $(14,5 \%)$.

Tabel 5.5 Gambaran frekuensi berdasarkan tingkat depresi pada lansia di Panti Darussa'dah dan An-Nur di Kota Lhokseumawe

\begin{tabular}{lcc}
\hline & Frekuensi (n) & Persentase (\%) \\
\hline Normal & 10 & 18,1 \\
Ringan & 12 & 21,8 \\
Sedang & 25 & 45,4 \\
Berat & 8 & 14,5 \\
\hline Total & 56 & 100,0 \\
\hline
\end{tabular}

Berdasarkan tabel 5.5 menunjukkan bahwa sebagian besar responden memiliki tingkat depresi terbanyak yaitu tingkat sedang sebanyak 25 orang $(45,4 \%)$ dan paling sedikit dengan tingkat depresi berat sebanyak 8 orang $(14,5 \%)$. 
Tabel 5.6 Gambaran frekuensi berdasarkan tingkat kecemasan pada lansia di Panti Darussa'dah dan An-Nur di Kota Lhokseumawe

\begin{tabular}{lcc}
\hline & Frekuensi (n) & Persentase (\%) \\
\hline Normal & 19 & 34,5 \\
Ringan & 18 & 32,7 \\
Sedang & 13 & 23,6 \\
Berat & 5 & 9,0 \\
\hline Total & 56 & 100,0 \\
\hline
\end{tabular}

Berdasarkan tabel 5.5 menunjukkan bahwa sebagian besar responden memiliki tingkat kecemasan terbanyak yaitu normal sebanyak 19 orang $(34,5 \%)$ dan paling sedikit dengan tingkat kecemasan berat sebanyak 5 orang $(9,0 \%)$.

\section{PEMBAHASAN}

\section{Gambaran Umum Hasil Penelitian}

\section{Karakteristik lansia di panti jompo Darussa'dah dan An-nur Lhokseumawe}

\section{Usia}

Umur dapat mempengaruhi kedewasaan seseorang. Stres lebih sering terjadi pada usia muda, umur rata-rata awitan antara 20-40 tahun. Faktor sosial sering menempatkan seseorang yang berusia muda pada risiko tinggi. Predisposisi biologic seperti genetik juga sering memberikan pengaruh pada seseorang yang berusia lebih muda. Walaupun demikian, depresi juga dapat terjadi pada anak-anak dan usia lanjut ${ }^{7}$.Stres mampu menjadi kronis apabila stres muncul untuk pertama kalinya pada usia 60 tahun keatas. Berdasarkan hasil studi pasien lansia yang mengalami depresi diikuti selama 6 tahun, kira-kira $80 \%$ tidak sembuh namun terus mengalami depresi atau mengalami depresi pasang surut ${ }^{8}$

\section{Jenis Kelamin}

Jenis kelamin berperan terhadap terjadinya stres. Ada perbedaan respon antara laki-laki dan perempuan saat menghadapi konflik. Otak perempuan memiliki kewaspadaan yang negatif terhadap adanya konflik dan stres, pada perempuan konflik memicu hormon negatif sehingga memunculkan stres, gelisah, dan rasa takut. Sedangkan laki-laki umumnya menikmati adanya konflik dan persaingan, bahkan menganggap bahwa konflik dapat memberikan dorongan yang 
positif. Dengan kata lain, ketika perempuan mendapat tekanan, maka umumnya akan lebih mudah mengalami stress ${ }^{7}$

\section{Pendidikan}

Tingkat pendidikan yang tinggi cenderung menyebabkan perubahan pada pola berpikir dan pandangan hidup. Seseorang dengan tingkat pendidikan yang tinggi akan mengalami perubahan pola berpikir dari tradisional ke arah yang lebih maju sehingga tidak hanya memandang persoalan dari satu sisi saja melainkan dapat dari berbagai sudut pandang ${ }^{7}$.

Pendidikan dapat mempengaruhi seseorang termasuk juga perilaku seseorang akan pola hidup terutama dalam memotivasi untuk sikap, berperan dalam pembangunan kesehatan. Makin tinggi pendidikan seseorang makin mudah menerima informasi, sehingga makin banyak pula pengetahuan yang dimiliki. ${ }^{9}$.

\section{Gambaran tingkat stres pada lansia Panti}

Jompo Darussa'dah dan An-Nur di Kota

\section{Lhokseumawe}

\section{Tingkat stres}

Berdasarkan hasil penelitian tingkat yang tidak mengalami stres sebanyak 8 orang $(14,5 \%)$, tingkat stres ringan sebanyak 14 orang $(25,4 \%)$, tingkat stres sedang sebanyak 25 orang $(45,4 \%)$. Tingkat stres ringan dikarenakan adanya dukungan dari lingkungan yang baik seperti keakraban sesama lansia lainnya serta dapat juga dikarenakan pola individu yang sudah baik terkait penyesuaian diri. Stres adalah suatu respon fisik normal terhadap suatu peristiwa yang membuat hidup seseorang menjadi terancam atau mengganggu keseimbangan dalam beberapa cara, seperti yang ketika seseorang mengalami tubuh akan melakukan pertahanan secara otomatis yang dikenal dengan sebutan fight or fight reaction atau reaksi stres ${ }^{10}$. Stres dalam kelurga dapat di sebabkan karena adanya konflik dalam keluarga, seperti perilaku yang tidak sesuai dengan harapan, keinginan dan cita-cita serta pendapat yang tidak dapat di satukan. Oleh karena itu keluarga bisa menjadi pengaruh stress ${ }^{\mathbf{1 1}}$. 


\section{Kesimpulan}

1. Gambaran tingkat stres terbanyak yaitu tingkat stres sedang $(46,4 \%)$ dan yang lansia paling sedikit yang tidak mengalami stres dan stres berat (14,3\%).

2. Gambaran usia terbanyak yaitu usia 60-70 sebanyak 55,4\%, jenis kelamin terbanyak yaitu perempuan sebanyak 64,2\%,sedangkan dari segi pendidikan terbanyak yaitu dasar (SD/SMP) sebanyak $(71,4 \%)$.

\section{Saran}

\section{Lansia}

Bagi lansia yang tinggal di panti disarankan untuk tetap menjaga kemampuan kognitif dengan cara melatih kemampuan memorinya misalnya mengisi teka-teki silang, membaca buku sebagai upaya untuk mencegah penurunan intelektual (pikun). Menghindari pemikiran negatif mengenai diri sendiri dan masa depan, menghilangkan perasaan bersalah atau menyesal mengenai kesalahan dimasa lalu, istirahat dengan cukup, dan menjaga pola makan.

\section{Peneliti selanjutnya}

Diharapkan untuk meneliti lebih lanjut pada variabel yang berbeda, agar dapat diperoleh informasi lebih kongkrit yang berhubungan denga tingkat stres pada lansia.

\section{Institusi pendidikan}

Hasil penelitian ini diharapkan dapat menjadi bahan pembelajaran atau referensi bagi mahasiswa, sehingga mahasiswa dapat mengembangkan wawasannya tentang asuhan keperawatan gerontik agar lebih berkualitas. 


\section{REFERENSI}

1. World Health Organization., 2012. Prevalence and related influencing factors of depressive symptoms. Archives of Gerontology and Geriatrics. Diakses pada tanggal 23 Desember 2016: http://www.sciencedirect.com/science/article

2. Ronald., 2015. Sehatdan Ceria di Usia Senja. Jakarta:Rineka Cipta, hal: 22-44.

3. Profil Kesehatan Provinsi Aceh., 2012. Profil Kesehatan di Aceh. Daerah Istimewa Aceh.

4. Indriana, Y., 2010. Gerontologi: Memahami Kehidupan Usia Lanjut. Semarang: Penerbit Universitas Diponegoro, hal: 77-99.

5. Dinas Sosial Kota Lhokseumawe., 2016. Profil Panti Jompo Kota Lhokseumawe. Aceh, Kota Lhokseumawe.

6. Depkes RI., 2013. Lansia, Bab 1. Jakarta, diakses pada tanggal 22 Desember 2016; www.depkes.go.id/downloads/Buletin\%20Lansia

7. Amir, L.M. (2008). Keperawatan lanjut usia. Yogjakarta : Graha Ilmu

8. Nevid., Spencer, AR., dan Greene, B. 2009. Psikologi Abnormal Edisi ke lima Jilid I. Jakarta: Penerbit Erlangga.

9. Notoatmodjo, S., 2007. Promosi Kesehatan dan Ilmu Perilaku. Jakarta: Rineka Cipta, hal: 60-88.

10. Stuart \& Sundeen., 2008. Instrument DASS (Depression Anxiety Stress Scales). Sukadiyanto.,2010. Stress dan cara menguranginya. Jurnal. FIK Universitas Negeri Yogyakarta.

11. Puspasari, S. (2009). Hubungan Kemunduran Fisiologis dengan Stres pada Lanjut Usia di Kelurahan Kaliwiru Semarang. Diakses pada tanggal 16 Maret 2016 darihttp://digilib.unimus.ac.id/gdl.php?modbrowse\&op=read\&id=jtptunim us-gdlseptikapus-5189\&PHPSESSID=1e67af6fa4bdd962b24ed311c991538. 